\title{
Author Correction: Supervaluation-Style Truth Without Supervaluations
}

\section{Johannes Stern ${ }^{1}$}

Received: 7 March 2019 / Accepted: 7 March 2019/Published online: 13 March 2019

(C) Springer Nature B.V. 2019

\section{Author Correction: J Philos Logic (2018) 47:817-850 \\ https://doi.org/10.1007/s10992-017-9451-0}

The original version of the article unfortunately contained a mistake. In the Acknowledgments section of the original version of the article, the grant number of the Marie Sklodowska-Curie Individual Fellowship supporting the author's work was misstated. The correct grant number of the MSC-Individual Fellowship TREPISTEME is 703539.

Publisher's Note Springer Nature remains neutral with regard to jurisdictional claims in published maps and institutional affiliations.

The online version of the original article can be found at https://doi.org/10.1007/s10992-017-9451-0

Johannes Stern

johannes.stern@bristol.ac.uk

1 Department of Philosophy, University of Bristol, Bristol, England 